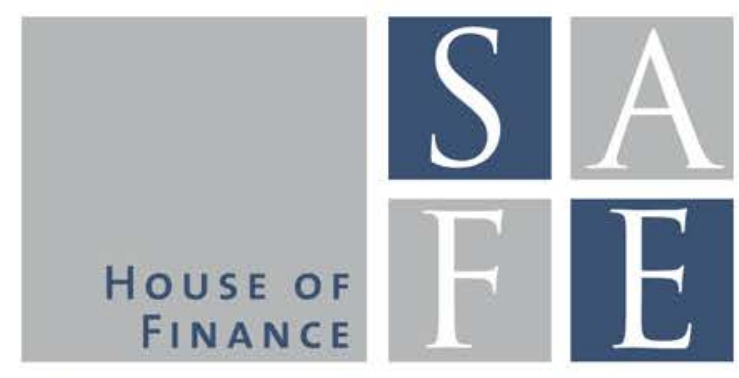

Working PAPER SERIES

Nina Biljanovska - Spyros Palligkinis

\title{
Control Thyself: Self-Control Failure and Household Wealth
}

SAFE Working Paper No. 69

SAFE I Sustainable Architecture for Finance in Europe 


\section{Non-Technical Summary}

In recent years, economic research has pointed out that self-contro/is a highly relevant concept for the study of household financial behavior. A number of studies find strong relationship between measures of self-control on the one hand and low saving rates or over-indebtedness of households on the other. These studies define self-control as the ability to resist temptation and provide theoretical justification and empirical evidence for its importance.

In this paper we employ a more comprehensive definition of self-control than the one usually used in the literature. This definition (proposed by psychology Professor Roy Baumeister) puts forward the idea that the strength of self-control depends crucially on three fundamental behavioral characteristics, referred to as ingredients of self-control. They consist of the ability for goal-setting, monitoring and commitment to earlier set goals. The theory suggests that strong self-control is exhibited by people who set long-term goals (e.g. lose $10 \mathrm{~kg}$ of body weight), keep track of the relevant behavior (e.g. regularly measure their weight and calorie intake), and have the ability to commit to earlier set goals (e.g. resist a more delicious meal that would jeopardize their effort). Importantly, failure of any of the three ingredients causes selfcontrol to fail.

We ask what the relationship between self-control failure and measures of household wealth is. To address this question, we use the Health and Retirement Survey, a standard dataset of US households aged 50 and above, which provides wealth information and a wide range of important household characteristics like age, education, health status, income etc. Crucially, the survey contains questions that allow us to measure all three ingredients of self-control and construct an overall measure of self-control failure.

Our findings, in line with existing studies, suggest that households that exhibit self-control failure have disproportionately low net worth. This result is present for a wide range of the wealth distribution but is stronger for more affluent households. Furthermore, self-control failure is strongly associated with lower levels of liquid, financial wealth, whereas the results on illiquid, real wealth are much weaker. This is compatible with the idea that conspicuous consumption is more likely to be financed by liquid than by illiquid wealth. Furthermore, we find a positive relationship between self-control failure and the probability of facing financial distress. Finally, we show that each individual ingredient of self-control, i.e. goal-setting, monitoring, and commitment, contributes quantitatively to this result.

Treating self-control as the result of these ingredients could leave room for enhancement, through appropriate financial literacy and related initiatives. In any case, it provides additional justification for existing policies: Financial education is important, not only because learning how to plan is necessary to quantify the goals of the household, but also because a household with a plan is less likely to act impulsively. Likewise, providing adequate financial information is important, not only for misinformed households to avoid mistakes, but also because an informed household exhibits more self-control. Finally, devices like automated transfers to savings accounts are not only simplifying the execution of a decision, but also represent a valuable tool for households to commit to their plans, against their impulses. 


\title{
Control Thyself: Self-Control Failure and Household Wealth*
}

\author{
Nina Biljanovska \\ Spyros Palligkinis \\ Goethe University Frankfurt Goethe University Frankfurt, SAFE
}

October 9, 2014

\begin{abstract}
We examine the relationship between household wealth and self-control. Although selfcontrol has been linked to consumption and financial behavior, its measurement remains an open issue. We employ a definition of self-control failure that follows literature in psychology, suggesting that three factors can render self-control defective: lack of planning, lack of monitoring, and lack of commitment to pre-set plans. Our measure combines those three ingredients and can be computed using a standard representative survey. We find that self-control failure is strongly associated with different household net wealth measures and with self-assessed financial distress.
\end{abstract}

Keywords: Self-Control, Household Wealth, Household Finance

JEL Classification: D01, D12, D14

${ }^{*}$ We thank Inaki Aldasoro, Enzo Cerletti, Olga Goldfine, Yigitcan Karabulut, Jian Li, Eirini Tatsi, Nate Vellekoop and especially our adviser Michael Haliassos for valuable comments. We further thank participants of the 7th RGS Doctoral Conference in Economics and of the Brown Bag Seminar at Goethe University. We gratefully acknowledge research support from the Research Center SAFE, funded by the State of Hessen initiative for research LOEWE. Contact at palligkinis@safe.uni-frankfurt.de. 


\section{Introduction}

In models of economic theory, self-control problems have been formulated as stemming from dynamic inconsistency in preferences, formally modeled by modifying the discount factor to generate a disproportionately higher discounting of the most recent future (see e.g. Laibson, 1997). ${ }^{1}$ An alternative modeling approach of self-control, adopted by Gul and Pessendorfer (2001, 2004), has been to introduce temptation, defined as individual's urge for current consumption, into the consumer's objective function. Furthermore, Thaler and Sherfin (1981) have introduced the dual-self models of self control, in which they treat the self as being a farsighted planner and a myopic doer at the same time. The results of this strand of the literature suggest that lack of self-control can explain high levels of credit card borrowing and of consumer credit. ${ }^{2}$

The empirical literature corroborates the theoretical findings by showing that self-control problems are associated with low levels of individuals' wealth accumulation (e.g. Ameriks et al., 2007), as well as high levels of financial indebtedness (e.g. Gathergood, 2012). However, despite the potential significance of self-control for households' financial well-being, as evident from theoretical and empirical studies, its measurement remains an open issue, as discussed in more detail later. The purpose of this paper is to contribute to this debate by introducing a self-control measure that can be incorporated in population-wide surveys and closely follows the literature in psychology.

Our study is motivated by a psychology theory, which was first introduced in Baumeister and Heatherton (1996) and then applied to consumer behavior in Baumeister (2002). It proposes that the strength of self-control depends crucially on three, more primitive, behavioral characteristics, referred to as ingredients of self-control: the ability for goal-setting, monitoring, and commitment to earlier set goals. This theory suggests that strong self-control is exhibited by people who set long-term goals (e.g. lose 10kg of body weight), keep track of the relevant behavior (e.g. regularly measure their weight or calorie intake), and have the ability to commit to earlier set goals (e.g. resist a more delicious meal that would jeopardize the effort). Importantly, as Baumeister (2002) argues, in order for self-control to be preserved all three ingredients have to be at play at the same time.

\footnotetext{
${ }^{1}$ Initially, time-inconsistency of decision making was introduced by Strotz (1956).

${ }^{2}$ See for example, Heidhues and Koszegi (2010), Bertaut et al. (2008), Fehr (2002), Laibson (1997).
} 
In this study we construct a self-control failure measure, which is grounded on the abovementioned theory and which takes all three constituents of self-control into account. The novelty of this measure is that it brings in two additional personality characteristics, i.e. planning and monitoring, that are potentially amenable to manipulation through policy initiatives (such as a financial literacy initiative). We empirically examine if self-control failure, measured in this way, matters for households' wealth level in general, as well as if it increases the probability of households facing financially distressful situations. Finally, we shed light on the extent that each individual ingredient contributes quantitatively to our results.

The way self-control is measured as a factor determining household's wealth depends on the definition employed, as well as on the dataset available. In the literature that uses micro-data from population representative household datasets, self-control has often been measured using proxy measures such as drinking and smoking (e.g. Bertaut et al., 2006). These measures can be highly correlated to consumption related self-control, but they still introduce measurement error since curing the symptom (smoking) may mask the disease (self-control failure), making the symptom (smoking) a noisy proxy. More importantly, they measure behavior that isn't related to financial decision making such that even if it were to be influenced (e.g. by helping people to give up smoking), this would not have an effect on households' financial wealth. Moreover, researchers have measured self-control in the laboratory. Probably the most famous experiment measuring self-control in this kind of setup is the one of Mischel et al. (1972). ${ }^{3}$ Other cases where economists have designed field and lab experiments to measure self-control include Della Vigna and Malmendier (2006), Houser et al. (2008) and Burger et al. (2009). In a prominent paper, Ameriks et al. (2007) measure self-control in a quasi-experimental setting and find that self-control correlates with household wealth measures in a sample of highly educated individuals.

In contrast to the studies mentioned above, we use the 2010 wave of the Health and Retirement Study (HRS) dataset, a representative sample of the US households that have at least one member aged above 50. In order to measure the self-control failure ingredients, we use the

\footnotetext{
${ }^{3}$ Walter Mischel designed the famous "Stanford marshmallow experiment," in which children were offered a choice between one small reward vs. two small rewards if they were able to delay gratification. In follow up studies, researchers have found that those children who were more patient had better life-outcomes, such as higher SAT-scores, better educational attainment, etc.
} 
"Life-style Questionnaire," answered by one third of the surveyed sample. The questionnaire supplements the prolific standard HRS study with rich information on psycho-social variables. Compared to studies using self-control proxies, the advantage of our approach is that we adopt a refined measure of self-control, that unveils elements of human behavior that could potentially be influenced. Furthermore, compared to existing studies focusing on experimental data, the advantage of using population-wide data is that it allows us to control for a large set of demographic, financial and behavioral characteristics of households and estimate the relationship that exists between self-control failure and households' wealth accumulation over and above standard wealth determinants.

A paper closely related to ours is Gathergood (2012), which examines the relationship between self-control, financial literacy and over-indebtedness among UK consumers. Another related study is McCarthy (2011), which examines the relationship of a certain set of behavioral traits, such as self-control strength, patience, and planning on the households' ability to stay out of financial trouble. The difference between these papers and ours, apart from the somewhat different focus, is that they measure self-control merely as impulsive behavior and/or inability to make plans ahead. The definition we employ is more comprehensive, including theirs as some of its ingredients. Furthermore, we aggregate those ingredients to a single measure in a non-linear way that is consistent with psychology theory.

Our main findings can be summarized as follows. Households that exhibit self-control failure have disproportionately low net worth. Furthermore, when we disaggregate net worth to net financial and real wealth, we find a negative relationship between self-control failure and net financial wealth, whereas the relationship to net real wealth is not significant. Using quantile regressions, we establish that the results hold for a wide range of the wealth distribution, with the ones above the median being stronger. In addition, we measure the probability of a household facing financial distress and we find statistically significant positive relationship between selfcontrol failure and the probability of facing financial distress. Finally, we find that all the individual self-control ingredients quantitatively contribute to the mentioned results.

The rest of the paper is organized as follows. The following two sections describe in more detail the ingredients of self-control, as well as the way we measure them in the data. Section 4 describes the econometric specification. Section 5 discusses the findings. Section 6 presents the 
robustness checks. Finally, section 7 contains our concluding remarks.

\section{Self-control failure}

In two influential papers, Baumeister (2002) and Baumeister et al. (1994), have established that self-control depends on three main behavioral characteristics that they call self-control ingredients: conflicting and unclear goals (standards), inadequate monitoring of one own's behavior, and lack of capacity to change one own's behavior. Each one of these ingredients can potentially render self-control defective. In what follows we explain each of these three ingredients that lead to self-control failure in more detail and provide an example of households' financial behavior that corresponds to the ingredient in question.

Standards. Standards refer to the ability of people to plan things ahead, to set goals, norms, and ideals for their own behavior. In this respect people can display either far-sighted or myopic behavior. ${ }^{4}$ An example of household's goal setting behavior may be the objective of buying a house and thus saving for a down-payment. As Baumeister (2002) argues, individuals who know exactly what they want to achieve, i.e. who have an established goal/plan in mind, are less likely to indulge in impulsive buying or overspending. Thus these people have the ability to better manage their wealth, are more likely to save, have higher net wealth positions, and are therefore also less likely to find themselves in a financially distressful situation. ${ }^{5}$

Monitoring. Monitoring refers to the ability to observe/follow/keep track of the relevant behavior. In terms of financial behavior and decision making, monitoring would imply systematically following how the household's financial resources are allocated. If people don't pay attention to "where their money goes," they would be more likely to spend on unnecessary purchases (even if their budget is tight) and thus they would be less likely to save. This would hinder the achievement of their preset goal (e.g. buying the house/saving for the down-payment).

Commitment. Commitment refers to one's ability to maintain attention and focus on preset goals in a face of temptation. In the situation when the individual has decided to buy a

\footnotetext{
${ }^{4}$ Baumeister et al. (1994) directly link standards to myopic behavior.

${ }^{5}$ Using a unique survey dataset, Ameriks at al. (2003) link self-control to the propensity to plan and find that people with higher such propensity tend to spend more time developing financial plans and as a result accumulate higher amount of wealth.
} 
house and has also monitored her spending behavior, the crucial question is whether she would be capable of resisting whatever unnecessary purchasing temptations might arise until she has saved enough for the down-payment. As Baumeister (2002) points out, there are three theories that could explain the ability to override incipient responses, which treat the self as a (i) limited resource, (ii) process that can be learned, or (iii) skill. Consideration of these theories is beyond the scope of our paper. Instead, we rely on a self-assessed variable evaluating the commitment of the individual to earlier set goals, as opposed to a deviation from them.

As the theory suggests, all three ingredients of self-control have to be at play at the same time such that self-control doesn't fail. Namely, if either one of the three components fails, the others are useless without it. This is the definition of self-control failure that we use in our study.

Lastly, it is important to mention that the main channel that we consider, through which self-control failure can affect households' wealth, is consumption. As Baumeister (2002) argues, impulsive consumption could lead to futile and prodigious expenditures, which in turn could result in low levels of wealth accumulation. In situations when a consumption triggered impulse arises, self-control, along with its individual components, can have a decisive role in resolving the "I shouldn't" dilemma, and, if strong, it could positively affect households' wealth positions.

\section{Measuring self-control failure}

We use the 2010 wave of the Health and Retirement Survey (HRS), a representative sample of US households who have at least one member aged above 50. The survey contains a wide range of socioeconomic variables, including household composition, income, real and financial wealth, education and occupational status. Furthermore, it provides a variety of health and cognition measures. Importantly, one third of participating households are randomly chosen and given to answer an extensive "Lifestyle Questionnaire," which contains an important number of psychosocial variables. Respondents are asked to report how satisfied they feel with their lives and relationships with others. They assess their inherent personality traits and they evaluate their behavior along a number of dimensions. It is in this questionnaire that we find the questions 
that we use to measure the three aspects of self-control ${ }^{6}$. Since only one third of the overall HRS respondents participate in the "Lifestyle Questionnaire," the sample size shrinks to 4,102 households in total.

We identify three statements in the dataset that correspond to the ingredients of self-control discussed. The statements used in measuring self-control failure are as follows:

- Goal setting: "I live one day at a time and don't really think about the future."

This statement determines people's ability to establish future goals/standards. It is formulated in a way that focuses on one's tendency to be myopic when making decisions, which is the counterpart of being far-sighted. Therefore this variable is given a negative sign with the following interpretation: the more myopic (in decision making) the person is, the less likely he is to set long-term goals for himself. The "Lifestyle Questionnaire" respondents are asked to rate their behavior on the scale of (i) strongly disagree, (ii) somewhat disagree, (iii) slightly disagree, (iv) slightly agree, (v) somewhat agree, to (vi) strongly agree. In figure 1 we present the sample distribution of goal setting ability (upper-left graph) using survey population weights. The median household slightly disagrees with the above statement. Figure 2 plots the relation between goal setting ability and average values of the financial variables that we consider, namely net total wealth, net financial wealth, and net real wealth. All three indicators of wealth correlate negatively with the statement above, implying that lower goal-setting ability results in lower wealth accumulation. For example, the average wealth of those who strongly agree with the lack of goal-setting statement is $58 \%$ lower than that of those who strongly disagree. Average financial and real wealth are $64 \%$ and $55 \%$ lower respectively.

- Monitoring: "I keep close track of where my money goes."

This statement measures how carefully the household monitors the allocations of its financial resources. Participants in the questionnaire rate their behavior on the same scale from (i) to (vi). In figure 1 , the sample distribution of households' monitoring ability (upper right graph)

\footnotetext{
${ }^{6}$ The 2010 wave of HRS also includes a special module on personality, where a subset of the respondents are asked questions related to self-control. Even though combining the lifestyle questionnaire and the personality module would be of great interest, the sample size decreases dramatically (only approx. 400 respondents answer both), which leads to insignificant results.
} 
is reported, which shows that $57 \%$ of the sample assess themselves as having strong monitoring ability. Figure 2 displays the relationship between monitoring ability and averages of the financial variables we consider. Although the correlation between monitoring and the different determinants of wealth is not as strong as the one of goal-setting ability, households who can better monitor their finances have higher net wealth. Particularly, the average wealth of those who strongly disagree with the monitoring statement is $27 \%$ lower than that of those who strongly agree. Average financial and real wealth are $35 \%$ and $21 \%$ lower respectively.

- Commitment: "I am an active person in carrying out the plans I set for myself."

This statement, as we have argued before, measures individual's ability to commit to earlier set goals. The ability to carry out pre-defined goals reflects individual's strength to resist immediate gratification or tempting distractions and thus to focus on long-term goals. Again, participants in the questionnaire rate their behavior on the same scale. Figure 1 reports the sample distribution of the commitment ability variable. We find that the median household somewhat agrees with the mentioned statement. Figure 2 displays a positive relationship between goalcommitment and averages of the financial variables. Specifically, on average households' total net wealth drops by approximately $61 \%$, and real and financial wealth by $69 \%$ and $59 \%$, respectively, if goal setting ability decreases from its highest to its lowest value.

Since the theory we employ states that self-control is not operative if either of the three ingredients fails, we construct our measure of self-control failure in the following manner. First, based on the questionnaire answers, we create a dummy variable for each ingredient of selfcontrol, which takes the value of one if the questionnaire respondent answers to the statement with somewhat disagree or strongly disagree(i or ii) and zero otherwise. ${ }^{7}$ These dummy variables flag whether the household has or does not have goal-setting, monitoring, and commitment ability, respectively. Using these dummy variables for the individual self-control ingredients, we set up the measure of self-control failure as a dummy variable, which takes the value of one if the household fails to satisfy either one of the self-control criterion measures (the self-control

\footnotetext{
${ }^{7}$ Note that, given the negative connotation of the statement determining goal-setting behavior, the dummy variable takes the value of one if the questionnaire correspondent answers to the statement with somewhat agree or strongly disagree(v or vi) and zero otherwise.
} 
ingredients). In this case, we say, the household exhibits self-control failure. ${ }^{8}$

Clearly, the choice of the threshold for the definition of the ingredient dummies above is necessarily somewhat arbitrary. We avoided creating ingredient dummies depicting the extreme outcome only (strongly dis-/agree), since there are few respondents giving this answer for the monitoring and commitment question (2.29\% and $2.88 \%$ of the sample respectively). In Section 6 we present some robustness checks for the case where we group the three dis-/agree answers together.

\section{Econometric specification}

\subsection{Wealth and financial distress}

We estimate the relationship between household net worth and self-control failure. An advantage of using HRS is that it provides us with accurate measures of household wealth, net of any liabilities. Furthermore, it allows us to distinguish between net financial and real wealth, thus enabling us to estimate the importance of self-control failure for each of the two wealth components individually. Net real wealth refers to the value of primary residence, various other forms of real estate, privately owned businesses and vehicles, all net of any outstanding loans that use these assets as collateral. Financial wealth includes amounts held in checking, savings or money market accounts and holdings in certificates of deposit, government savings bonds and T-bills, bonds, stocks, mutual funds and investment trusts, as well as any other savings. We further include the net value of IRA and Keogh accounts and subtract the value of any uncollateralized debt. All these variables are aggregated on the household level and missing values are imputed by RAND corporation. Given that the wealth variables are highly skewed we also normalize

\footnotetext{
${ }^{8}$ An alternative approach would be to conduct factor analysis, which is the standard approach in personality psychology (see Almound et al., 2011, for a survey of the research in the intersection of personality psychology and economics). This approach aims at constructing one factor out of the questions used and it operates under the assumption that the questions are measuring the same underlying personality trait. In our setting, however, the three questions correspond to three different traits, which mirrors to the statistical results of the factor analysis we have conducted: the three questions retain a high level of "uniqueness" (above 80\%), which indicates that the factor created is not valid. Principal Component Analysis yields similar results: there exists no component that captures enough variation of all three ingredient variables.
} 
them ${ }^{9}$.

We further study whether self-control failure matters for the probability of a household falling in financial distress. This is not a priori clear, even if self-control failure affects households' net worth negatively. People tend to ration their consumption behavior when the risk of them facing financial distress is higher. Thus they are more likely to react in order to avoid such situation. The Lifestyle Questionnaire of HRS provides us with the financial distress measure we use, through the following question:

- Financial distress: "How difficult is it for (you/your family) to meet monthly payments on (your/your family's) bills?"

Respondents are answering $\mathrm{n}$ a 1-to-5 scale, which ranges from not at all difficult to completely difficult. We construct our financial distress measure by crating a dummy variable that takes the value one when respondents answer very difficult and completely difficult, and zero otherwise. In Figure 3 we display the distribution of the original measure, using survey population weights. Under our assumptions, $8.80 \%$ of the sample is facing financial distress. Gatherwood (2012) uses a similar question, which he also calls self-reported financial distress to measure over-indebtedness. McCarthy (2011) uses the same definition with us.

\subsection{Controls}

In our analysis we control for a rich set of standard demographic and socioeconomic status characteristics, as well as for cognitive ability and health. All these variables are known to be wealth determinants and, simultaneously, are correlated to our self-control failure measure. In the subsections below, we give a detailed discussion of the controls included.

\section{2.a Cognitive ability}

Cognitive ability stands out as an important personal trait, as it is arguable that certain individuals may abstain from planning and monitoring just because they do not have the necessary skill for that. At the same time, lower cognitive ability can have a negative effect on wealth, through

\footnotetext{
${ }^{9}$ We use the inverse hyperbolic sine (IHS) transformation, $\log \left(x+\left(x^{2}+1\right)^{1 / 2}\right)$. IHS is near-logarithmic and, at the same time, it is defined also for non-positive net wealth values.
} 
poor income generation and miss-management. Christelis et al. (2010) find that low-cognitive ability individuals are less likely to participate in the stock market and stress the point that, due to low cognition, these individuals face higher fixed participation costs. This means that the investment opportunity set of those households is more constrained than that of households with higher cognition, which results in lower wealth accumulation.

We measure cognitive ability using two questions from the cognition section of HRS (see Christelis et al., 2010 for measures using SHARE data). The first one is a memory indicator. Respondents are told ten words and then they are immediately asked to list as many of them as they can remember. After that, they are asked a few other cognition questions and then, finally, they are asked to list the ten words again. The number of the words they manage to remember at the second time is recorded as "delayed memory" measure. The second variable we use measures numeracy. Respondents are asked to start from 100 and subtract 7 for five consecutive times. Our variable counts how many of these subtractions were correct. Table 1 contains the descriptive statistics of these (and the other) variables we use. The average household of our sample scores 4.5 out of 10 in the delayed memory test and 3.8 out of 5 in the numeracy test.

\section{2.b Health status}

Health status is another determinant of wealth that can correlate to our self-control measure. Individuals with very poor health are probably (and sadly) less prone to make long term plans and find it harder to monitor their expenses. The relationship can also work in the opposite direction, since personality traits, including self-control can lead to better health outcomes and longevity. ${ }^{10}$ On the other hand, health is an important factor for wealth accumulation, as it correlates positively with income and negatively with out-of-pocket medical expenses. The latter tend to be sizable for the aged sample that we have. To account for health status, we use a measure of self-reported health, where individuals rate their health from 1 to 5 . For our sample, the mean self-assessed health score is 2.5 .

\footnotetext{
${ }^{10}$ See e.g. Hampson et al. (2007).
} 


\section{2.c Household income}

Household income is an extremely important variable for wealth accumulation and the probability of financial distress. We also expect it to interact with self-control through at least two different channels. On the one hand, workers who exhibit self-control, and especially those who set goals and are active in reaching them, are expected to have more successful careers and reach higher levels of income, and therefore wealth, as a result. ${ }^{11}$ On the other hand, households that face self-control failure and consume excessively as a result, may choose to increase their labor supply or seek better wages in order to avoid reducing their savings or borrow. These effects are distinct from the consumption-related channel that we explore in this paper.

To account for these effects, we include normalized income in our analysis. Furthermore, and in order to capture the non-linear way that accumulated wealth and current income are linked (see van Rooij et al., 2012), we further include its square and cube.

\section{2.d Age}

Age has a complicated, non-linear relationship to income and wealth, as it proxies for work experience, time spent accumulating wealth and occurrence of health expenditures. In particular, income is found to follow a hump-shaped age profile which peaks at mid-fifties for most people. Furthermore, Ameriks et al. (2007) report that older people display more self-control than the young. This finding also points to the possibility that self-control and financial behavior interact through a learning mechanism. We think that this learning process is probably finished by the time people enter our sample, which is when they turn 50, but we still include age in our regressions. In order to account for the non-linearities, we additionally include age squared.

\section{2.e Education}

Educational attainment is a strong predictor of wealth and income. Educated people get better paid jobs and are more likely to receive bequests form their parents, who are more wealthy than average. Also, as Almlund et al. (2011) survey, traits related to self-control are related to better educational attainment. The educated exhibit more self-control, as successful studies require a

\footnotetext{
${ }^{11}$ See Bowles et al., 2001, for a discussion of how personality traits increase income through an increase in productivity.
} 
certain level of self-discipline, planning and commitment. In our regressions we include three dummy variable for high-school graduates, people who have had some college education and, finally, college graduates. Our missing category are people who have less than a high-school degree.

\section{2.f Other Controls}

We finally include occupational status as a dummy that takes the value one if the person is not currently working, as well as variables containing race information and household composition. All these have been found to be important factors for household wealth accumulation. Summary statistics of all these variables are also included in Table 1.

Finally, we note that, and as usual for a survey of its kind, HRS contains some of its variables measured at an individual level (e.g. age and education) and others at a household level (e.g. wealth and income). In the household finance literature, authors tend to treat the individual level variables in two different ways. Some authors aggregate the individual responses of the spouses/partners to a single value, taking averages or the maximum values (see e.g. Christelis et al. 2010). Others use the financial respondent's individual responses as representative of the household, making the assumption that the person who answers the financial questions is the most relevant. In our empirical analysis, our approach the latter, since we believe that the financial respondent's self-control probably the strongest relationship to household wealth. In section 6 , we present some robustness checks where we re-run our baseline regressions with our self-control measure aggregated on the household level.

\section{$5 \quad$ Results}

\subsection{Self-control failure and net wealth}

We model the relationship between self-control failure and net worth using an OLS regression with robust standard errors. Our specification is:

$$
Y_{i}=b_{0}+b_{1} \cdot F_{i}+b_{2}^{\prime} X_{i}+u
$$


where $i$ is the index for the households of our sample, $Y_{i}$ is normalized net worth, $F_{i}$ is our self-control failure measure and vector $X$ includes the set of controls that have been presented in the previous section.

In the first column of Table 2, we report the average marginal effects of our net worth regression. ${ }^{12}$ Households which fail to exhibit self-control have disproportionately low wealth, with self-control failure being associated with a $0.75 \%$ decrease of the net worth of households. The result is statistically significant at all conventional levels. As we have discussed, our controls include all the standard socioeconomic variables that are considered to be wealth determinants. This implies that our results display a relationship between the two variables that exists over and above all those other factors.

Our controls have signs that are in line with what is standard in the literature. Cognitive abilities, income, education and age are positively associated with wealth, as is the dummy variable indicating that household has a couple (spouses or partners). On the other hand, the number of household residents and the existence of a spouse with Hispanic or black background has a negative relationship to wealth.

We further proceed to divide net worth to its net real and net financial wealth component and re-estimate our model. This time, in the case of the net real wealth regression, we additionally include net financial wealth in the regressors, and vice versa. The next columns of Table 2 , display the results; we find a negative relationship between self-control failure and both measures of wealth, but only the relationship with financial wealth is statistically significant. Self-control failure is associated with a decrease of $0.79 \%$ of net financial wealth and the result is significant at the $1 \%$ level.

This difference in the significance of the relationship for the two wealth components points to the fact that impulsive consumption, which is the channel through which self-control failure affects wealth, is more likely to have an immediate impact on liquid holdings than on illiquid assets. Real wealth will only be implicitly affected, since increased consumption means that households accumulate less wealth and therefore find it harder to acquire real assets. These results

\footnotetext{
${ }^{12}$ Throughout the paper, we report average marginal effects results for all our estimations, including for OLS regressions. This way, we keep our tables more compact with respect to the non-linear relationships of wealth to age and income (modeled as 2 nd and 3rd order polynomials respectively)
} 
are in line with those of Ameriks et al. (2007), who find that self-control plays a significant role in determining non-retirement financial assets, which are considered to be more liquid compared to the retirement assets. For this class of assets, they find that self-control does not play a role.

\subsection{Self-control failure across the wealth distribution}

We extend our analysis by evaluating whether the relationship of self-control failure and household net worth remains strong across the entire wealth distribution. We estimate quantile regressions of our wealth measures using the same regressors as in the previous section. In Table 3 we present the coefficients of our self-control failure measure for the regressions of the three wealth variables, estimated at the $10 \%, 25 \%, 50 \%, 75 \%$ and $90 \%$ level of their distribution. Self-control failure has a negative relationship with household net worth across most of its distribution, the results being non-significant at the 10 th quantile, significant at the $10 \%$ for the 25 th quantile, at the $5 \%$ level for the 50 th and 75 th and at the $1 \%$ for the 90 th. Results on net financial wealth range from non-significant at the 10th quantile to significant at the $1 \%$ level for the levels above the 50 th quantile. The relationship is significant at the $10 \%$ level for the 25 th quantile and at the $5 \%$ for the median. Finally, the results of net real wealth are non-significant for most of the distribution and only become significant at the $5 \%$ level for the 90th quantile of the distribution, that is the wealthiest tail.

Our results indicate that the relationship of self-control to net worth and net financial wealth is strong across a wide range of the wealth distribution. It also appears to be stronger at the right tail, where even the net real wealth relationship is becoming significant.

\subsection{Self-control failure and financial distress}

We model financial distress as a latent variable that is related to self-control failure through the following specification:

$$
Y_{i}^{*}=b_{0}+b_{1} \cdot F_{i}+b_{2}^{\prime} X_{i}+u
$$

where, again, $i$ is the index for the households of our sample, $Y_{i}^{*}$ is financial distress as a latent variable, $F_{i}$ is our self-control failure measure and vector $X$ includes the set of controls of the previous section, as well as normalized real and financial wealth. Our financial distress measure 
is a dummy variable and therefore we estimate the model using an probit regression.

In Table 4 we report the average marginal effects of self-control failure for the outcome of financial distress, adjusted using the survey population weights. For households whose selfcontrol fails, the probability of facing financial distress increases by $3.19 \%$, which represents a $35.5 \%$ increase from the unconditional levels of $8.5 \%$. The result is statistically significant at all conventional levels.

The findings suggest a strong positive relationship between the occurrence of self-control failure and the probability of facing financial distress. This highlights the importance of selfcontrol for extreme situations that go beyond standard wealth accumulation. Furthermore, the relationship exists over and above the effects of all the standard socioeconomic status variables we control for, including wealth itself.

\subsection{The role of self-control ingredients}

The self-control failure measure we use is in line with the theoretical psychology model that we employ. However, we need to exclude the possibility that one or more of the variables we use is actually redundant or, differently put, that our empirical results are driven by the relationship of wealth to only one or two of our ingredients. In addition, it is important, from an empirical perspective, to assess to what extent each of those three ingredients contributes to our results.

To test the relative importance of the three ingredients of self-control, we re-estimate our models, replacing the original measure with the three dummies that flag failure of the three ingredients, as defined in section 3. In Table 5, we present the results for the wealth variables. The levels of significance vary a lot for different wealth measures and different variables. Failure of standards has relationships to net worth and net real wealth, which are significant at the $5 \%$ and the $10 \%$ level respectively. Monitoring is significant at $1 \%$ for net financial wealth and at $10 \%$ for net worth. Finally, commitment failure is significantly associated with net worth at the $1 \%$ level and with the other two measures at the $10 \%$. All the significant co-efficients are negative, in line with what theory would suggest. The results match the ones of the baseline specification, since the stronger relationships occur for net worth and net financial wealth, which have the strongest relationship to our self-control failure measure as well. On the other hand, 
net real wealth, whose relationship to self-control failure is non-significant in the baseline results, is only weakly related to the ingredient measures.

In Table 6, we present the relationship between financial distress and the three ingredients. Financial distress is not associated to standards failure, whereas the relationship to the other two variables is significant at the $1 \%$ level. All three relationships are positive.

The key takeaway from this analysis is that different ingredients of self-control can be more important than others for different settings, but they all contribute to our baseline results. Therefore, our self-control failure measure is not only in line with Baumeister's theory, but it also consists of ingredients that are associated with household wealth and/or financial distress measures on a stand-alone basis.

\section{Robustness checks}

The channel that we emphasize, through which self-control can affect household wealth, is consumption. Households whose self-control fails consume more than what would be ex ante optimal. A competing explanation could be that self-control and wealth are related through impulsive behaviour in investment decisions. According to this channel, people whose self-control fails are more prone to over-trading, which in turn is related to higher transaction costs and lower wealth accumulation. In order to account for this possibility, we re-estimate our regressions for the sub-sample of non-stockholders. In Tables 7 and 8, we report the findings, which indicate that the results do not change. Whatever effect over-trading might have on observed wealth levels and financial distress, it is not overshadowing our results.

To further check the robustness of our findings, we use an alternative definition for the measure of our self-control failure ingredients and, therefore, for the self-control failure measure itself. Instead of indexing failure of goal-setting when the original variable takes the values "strongly agree" and "somewhat agree", we use "slightly agree" as well. Likewise, for monitoring and commitment failure we use "slightly disagree" on top of the "somewhat disagree" and "strongly disagree" outcomes. In Table 9, we see that the results for net worth are again statistically strong, and so are the ones for financial wealth.Furthermore, our coefficient in the case of the net real wealth regression becomes significant at the $5 \%$ level. Its magnitude is approximately half the 
one of the financial wealth regression (-0.314 instead of -0.621). In Table 10 we report the average marginal effects for the case of financial distress. Self-control failure is still positively associated with increased probability of facing financial distress, with the coefficients being significant at the $1 \%$ level.

We additionally test to what extent our results are sensitive to the fact that we only use the individual level responses of the financial respondent. We aggregate the responses of the two spouses/partners, where applicable, as follows: we take the age of the household to be the mean of the two. For cognitive ability measures and education, we take the maximum attainment. We also use the maximum of the scores for the financial distress variable. Our basic financial literacy dummy takes the value 1 if either of the two answers correctly. Also, our race dummies (black and Hispanic) take the value 1 if either of the two belongs to it and the variable for being out of work is 1 if either of the two does not work. For self-reported health, we use the minimum of the two instead. Regarding the measures of our self-control ingredients, we use the maximum score for the planning variable and the minimum one for monitoring and commitment to change. In Table 11 we report our findings; our estimates are very similar to the ones of the baseline results. Re-estimating the financial distress specification with these data (not reported in the paper) gives exactly the same picture.

We also experiment by including a measure of basic financial literacy in our specification. Basic financial literacy is defined as the ability of households to grasp rather basic financial concepts like interest compounding. We exploit a question that asks respondents to give the amount they would receive if they where to invest 200 US dollars for two years in an account that offered them $20 \%$ per annum. We construct a dummy for those respondents that gave the right answer and find that $14.3 \%$ of our sample do. Van Rooij et al. (2012) use an extended measure that includes our interest compounding measure and a measure of numeracy, similar to the one used in the cognitive abilities section. The problem with this variable is that it $19 \%$ of our sample do not answer it and this leads to selection bias of our sample towards the rich. Inclusion of this variable does not change our baseline results much (full tables available upon request) and its coefficient is never significant for any of our specifications.

Despite all the checks we have conducted, we acknowledge that our analysis can be open to the consequences of potential reverse causality. Still, we believe that these concerns are alleviated by 
the fact that our goals and our commitment variable are not referring to financial behavior. They are therefore more likely to depict broader individual behavior than specific financial planning or commitment to financial goals. This broader behavior, which could include also cases like planning to lose weight and sticking to a decided diet, are less likely to be affected by changes in wealth. This criticism remains however for our monitoring measure.

\section{Concluding remarks}

The relationship between self-control and households' wealth has been discussed widely in the literature: those households, that exhibit high levels of self-control strength have higher wealth accumulation. In this paper we have defined a measure of self-control failure by employing a theory from psychology, proposed by Baumeister and co-authors (1996, 2002), which suggests that three factors - goal-setting, monitoring, and commitment - play an important role in determining self-control strength. Based on this definition of self-control, we measure self-control failure in the HRS to examine if it matters for household wealth outcomes, particularly net wealth (overall, real, and financial) and for households facing situations of financial distress. In summary, we find that self-control failure is strongly associated with households' finances measured in a population-wide representative survey. Specifically, we find that self-control failure is negatively correlated with both overall household net worth and net financial wealth. The relationship to net real wealth is not significant, which is in line with the idea that compulsive consumption is financed through financial resources, rather than through real assets.

Furthermore, using quantile regressions, we confirm that the relationship between self-control failure and wealth outcomes is strong for a wide range of the wealth distribution, and it becomes more significant for wealthier households. A more detailed analysis also shows that all the individual components that cause self-control to fail quantitatively contribute to these results. Finally, we find a strong positive relationship between the occurrence of self-control failure and the probability of facing financial distress.

We believe that measuring self-control (failure) by decomposing it to a set of ingredients emphasizes that it should not be taken for granted but is amenable, at least in part, to manipulation through appropriate financial literacy and related initiatives. In any case, it provides 
additional justification for existing policies: Financial education is important, not only because learning how to plan is necessary to quantify the goals of the household, but also because a household with a plan is less likely to act impulsively. Likewise, providing adequate and readable financial information is important, not only for misinformed households to avoid mistakes, but also because an informed household exhibits more self-control. Finally, devices like automated transfers to savings accounts are not only simplifying the execution of a decision, but also represent a valuable tool for households to commit to their plans, against their impulses. Self-control assistance can also be a convincing argument for households to participate in financial education programs and to make use of monitoring services and commitment devices. It is a fairly easily understood concept and one that, arguably, people can relate to. 


\section{References}

[1] Almlund, M., Lee Duckworth, A., Heckman, J. and Kautz, T., (2011) Personality Psychology and Economics, in: Hanushek, E.A., Machin, S. and Woessmann, L. (eds.), Handbook of the Economics of Education, Vol.4. Elsevier B.V., pp. 1-158.

[2] Ameriks, J., Caplin, A. and Leahy, J. (2003) Wealth Accumulation and the Propensity to Plan, The Quarterly Journal of Economics 118(3), 1007-1047.

[3] Ameriks, J., Caplin, A., Leahy, J. and Tyler, T. (2007) Measuring Self-Control Problems, American Economic Review 97(3), 966-972.

[4] Baumeister, R. F. (2002) Yielding to temptation: Self-control failure, impulsive purchasing, and consumer behavior, Journal of Consumer Research 28(4), 670-676.

[5] Baumeister, R.F. and Heatherton, T. F. (1996) Self-regulation failure: An overview, Psychological Inquiry 7, 1-15.

[6] Baumeister, R. F., Heatherton, T. F. and Tice, D. M. (1994) Losing control: How and why people fail at self-regulation, Academic Press, San Diego, California.

[7] Bertaut, C., Haliassos, M. and Reiter, M. (2009) Credit Card Debt Puzzles and Debt Revolvers for Self Control, Review of Finance 13(4), 657-692.

[8] Bowles, S., Gintis,H. and Osborne, M. (2001) The Determinants of Earnings: A Behavioral Approach.Journal of Economic Literature 39(4), 1137-1176.

[9] Burger, N., Charness, G. and Lynham J. (2009) Three field experiments on procrastination and willpower, unpublished working paper, Rand Corporation, University of California at Santa Barbara, University of Hawai'i at Manoa.

[10] Christelis, D., Jappelli, T. and Padula, M. (2010) Cognitive abilities and portfolio choice, European Economic Review 54(1), 18-38.

[11] DellaVigna, S. and Malmendier U. (2006) Paying not to go to the gym, American Economic Review 96, 694-719. 
[12] Fehr, E. (2002) The economics of impatience, Nature 2, 269-272.

[13] Gathergood, J. (2012) Self-control, financial literacy and consumer over-indebtedness, Journal of Economic Psychology 33(3), 590-602.

[14] Gul, F. and Pesendorfer, W. (2001) Temptation and Self-Control, Econometrica 69(6), 1403-1435.

[15] Gul, F. and Pesendorfer, W. (2004) Self-Control and the Theory of Consumption, Econometrica 72(1), 119-158.

[16] Hampson, S.E., Goldberg, L.R., Vogt, T.M. and Dubanoski, J.P. (2007) Mechanisms by Which Childhood Personality Traits Influence Adult Health Status: Educational Attainment and Healthy Behaviors, Health Psychology 26(1),121-125.

[17] Heidhues, P., Koszegi, B. (2010) Exploiting naiveté about self-control in the credit market, American Economic Review 100, 2279-2303

[18] Houser, D., Reiley, D. H. and Urbancic,M. B. (2008) Checking out temptation: A natural experiment with purchases at the grocery register, unpublished working paper, University of California, Berkeley, University of Arizona, and George Mason University.

[19] Laibson, D., (1997) Golden Eggs and Hyperbolic Discounting, The Quarterly Journal of Economics 112(2), 443-477.

[20] McCarthy, Y. (2011) Behavioural characteristics and financial distress, ECB Working Paper Series No. 1303.

[21] Mischel, W., Ebbesen, E. B. and Raskoff Zeiss,A. (1972) Cognitive and attentional mechanisms in delay of gratification, Journal of Personality and Social Psychology 21(2), 204-218.

[22] van Rooij, M., Lusardi, A. and Alessie, R. (2012) Financial Literacy, retirement planning and household wealth, The Economic Journal 122, 449-478. 



Figure 1: Sample distributions of self-control ingredients. 
Table 1: Sample summary statistics

\begin{tabular}{lccccc}
\hline \hline & & & & & \\
& Observations & mean & sd & min & max \\
\hline Self-control failure & 4102 & 0.272 & 0.445 & 0 & 1 \\
& & & & & \\
live life one day at a time & 4102 & 2.686 & 1.653 & 1 & 6 \\
keep close track of money & 4102 & 5.228 & 1.180 & 1 & 6 \\
active in carrying out own plans & 4102 & 4.775 & 1.244 & 1 & 6 \\
& & & & & \\
net worth (000's) & 4102 & 464.4 & 879.9 & -843.5 & 18572.0 \\
net financial wealth (000's) & 4102 & 218.6 & 552.5 & -1242.0 & 13622.3 \\
net real wealth (000's) & 4102 & 245.8 & 580.3 & -440.7 & 18505.0 \\
financial distress & 4004 & 0.085 & 0.279 & 0 & 1 \\
& & & & & \\
total income (000's) & 4102 & 64.2 & 74.5 & 0 & 1036.7 \\
is a couple & 4102 & 0.556 & 0.497 & 0 & 1 \\
number of hhd residents & 4102 & 1.913 & 0.965 & 1 & 11 \\
race: is hispanic & 4102 & 0.054 & 0.225 & 0 & 1 \\
race: is black & 4102 & 0.086 & 0.281 & 0 & 1 \\
education: high-school graduate & 4098 & 0.350 & 0.477 & 0 & 1 \\
education: some college & 4098 & 0.251 & 0.434 & 0 & 1 \\
education: college and above & 4098 & 0.278 & 0.448 & 0 & 1 \\
age in years & 4102 & 68.65 & 9.78 & 50 & 101 \\
not working for pay & 4097 & 0.618 & 0.486 & 0 & 1 \\
delayed word recall & 4037 & 4.472 & 1.864 & 0 & 10 \\
serial 7s & 4037 & 3.784 & 1.552 & 0 & 5 \\
performs interest compounding & 3151 & 0.144 & 0.351 & 0 & 1 \\
self-reported health & 4099 & 3.250 & 1.058 & 1 & 5 \\
\hline \hline
\end{tabular}



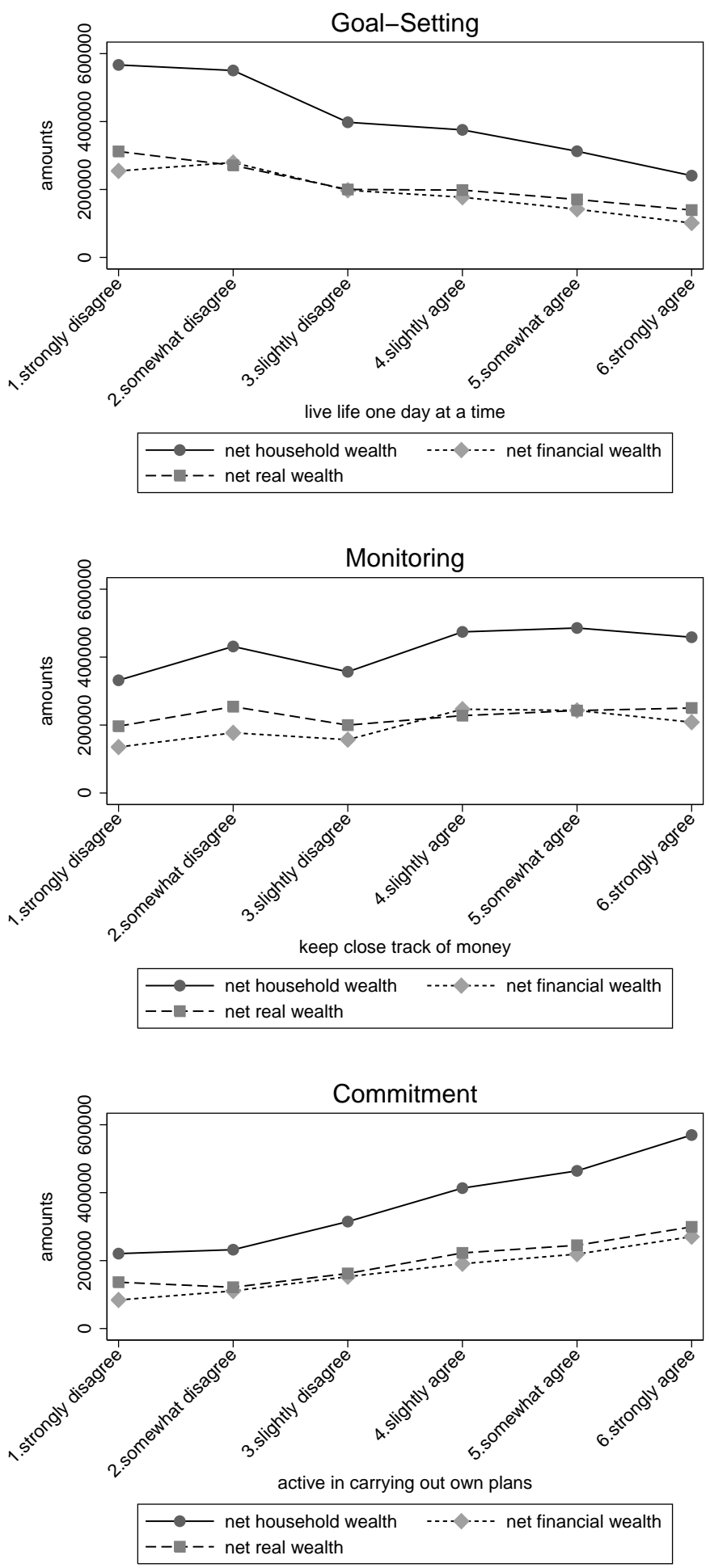

Figure 2: Wealth and self-control ingredients. The figures plot the mean of net worth, net financial and net real wealth across different values of the self-control ingredients. 
Financial Distress

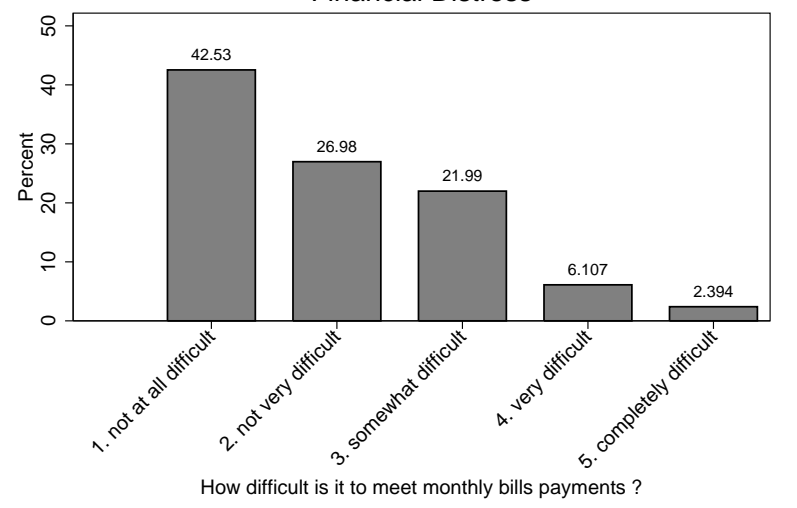

Figure 3: Sample distribution of financial distress measure. 
Table 2: Net Wealth and Self-control Failure

\begin{tabular}{|c|c|c|c|c|c|c|}
\hline \multirow[b]{2}{*}{ Self-control failure } & \multicolumn{2}{|c|}{ "net worth (IHS) } & \multicolumn{2}{|c|}{ " net real wealth (IHS) } & \multicolumn{2}{|c|}{ " net financial wealth (IHS) } \\
\hline & $-0.748^{* * *}$ & $(0.000)$ & -0.267 & $(0.115)$ & $-0.787 * * *$ & $(0.001)$ \\
\hline total income (IHS) & $1.369^{* * *}$ & $(0.000)$ & $0.677^{* * *}$ & $(0.000)$ & $1.752^{* * *}$ & $(0.000)$ \\
\hline is a couple & $0.972^{* * *}$ & $(0.000)$ & $1.233^{* * *}$ & $(0.000)$ & 0.368 & $(0.218)$ \\
\hline number of hhd residents & $-0.217^{*}$ & $(0.092)$ & -0.00662 & $(0.949)$ & $-0.899 * * *$ & $(0.000)$ \\
\hline race: is hispanic & $-1.790^{* * *}$ & $(0.000)$ & $-1.035^{* * *}$ & $(0.010)$ & $-2.623 * * *$ & $(0.000)$ \\
\hline race: is black & $-1.626^{* * *}$ & $(0.000)$ & $-0.768 * * *$ & $(0.003)$ & $-2.620 * * *$ & $(0.000)$ \\
\hline education: high-school graduate & $0.804^{* * *}$ & $(0.008)$ & $0.749 * * *$ & $(0.003)$ & $0.839^{* *}$ & $(0.018)$ \\
\hline education: some college & $1.001^{* * *}$ & $(0.002)$ & $0.660^{* *}$ & $(0.018)$ & $1.410^{* * *}$ & $(0.000)$ \\
\hline education: college and above & $1.306^{* * *}$ & $(0.000)$ & $0.723^{* *}$ & $(0.011)$ & $2.527^{* * *}$ & $(0.000)$ \\
\hline age in years & $0.139^{* * *}$ & $(0.000)$ & $0.0572^{* * *}$ & $(0.000)$ & $0.154^{* * *}$ & $(0.000)$ \\
\hline not working for pay & 0.238 & $(0.275)$ & -0.125 & $(0.482)$ & $1.293^{* * *}$ & $(0.000)$ \\
\hline delayed word recall & -0.00272 & $(0.954)$ & 0.0349 & $(0.435)$ & 0.0332 & $(0.586)$ \\
\hline serial $7 \mathrm{~s}$ & $0.196^{* * *}$ & $(0.004)$ & $0.124^{* *}$ & $(0.025)$ & $0.274^{* * *}$ & $(0.000)$ \\
\hline self-reported health & $0.569^{* * *}$ & $(0.000)$ & $0.315^{* * *}$ & $(0.000)$ & $0.676^{* * *}$ & $(0.000)$ \\
\hline net financial wealth (IHS) & & & $0.126^{* * *}$ & $(0.000)$ & & \\
\hline net real wealth (IHS) & & & & & $0.268^{* * *}$ & $(0.000)$ \\
\hline Observations & 4025 & & 4025 & & 4025 & \\
\hline Adj. $R^{2}$ & 0.201 & & 0.195 & & $0: 288$ & \\
\hline
\end{tabular}

Note: We run OLS with robust S.E. and the coefficients can be interpreted as the average marginal effects of self control failure. For the real wealth regression we include financial wealth as an explanatory variable, and vice versa.

$p$-values in parentheses: ${ }^{*} p<0.1,{ }^{* *} p<0.05,{ }^{* * *} p<0.01$ 
Table 3: Self-control Failure quantile regression coefficients

\begin{tabular}{|c|c|c|c|c|c|}
\hline Quantiles: & $10 \%$ & $25 \%$ & $50 \%$ & $75 \%$ & $90 \%$ \\
\hline Net worth & $\begin{array}{c}-1.143 \\
(0.1166)\end{array}$ & $\begin{array}{c}-0.409^{*} \\
(0.0804)\end{array}$ & $\begin{array}{c}-0.172^{* *} \\
(0.0331)\end{array}$ & $\begin{array}{l}-0.143^{* *} \\
(0.0117)\end{array}$ & $\begin{array}{c}-0.155^{* * *} \\
(0.0088)\end{array}$ \\
\hline Net financial wealth & $\begin{array}{c}-1.012 \\
(0.3357)\end{array}$ & $\begin{array}{l}-0.671^{*} \\
(0.0816)\end{array}$ & $\begin{array}{c}-0.408^{* *} \\
(0.0133)\end{array}$ & $\begin{array}{c}-0.337^{* * *} \\
(0.0046)\end{array}$ & $\begin{array}{c}-0.262^{* * *} \\
(0.0057)\end{array}$ \\
\hline Net real wealth & $\begin{array}{c}0.035 \\
(0.9329)\end{array}$ & $\begin{array}{c}-0.146 \\
(0.5859)\end{array}$ & $\begin{array}{c}-0.025 \\
(0.7485)\end{array}$ & $\begin{array}{c}-0.086 \\
(0.1074)\end{array}$ & $\begin{array}{c}-0.139 * * \\
(0.0376)\end{array}$ \\
\hline
\end{tabular}


Table 4: Probability of Financial Distress and Self-Control Failure

\begin{tabular}{|c|c|c|}
\hline & \multicolumn{2}{|c|}{$\overline{\operatorname{Pr}(\text { Paying bills }=\text { very difficult })}$} \\
\hline Self-control failure & $0.0319 * * *$ & $(0.000)$ \\
\hline net financial wealth (IHS) & $-0.00536^{* * *}$ & $(0.000)$ \\
\hline net real wealth (IHS) & $-0.00291^{* * *}$ & $(0.000)$ \\
\hline total income (IHS) & $-0.0234^{* * *}$ & $(0.000)$ \\
\hline is a couple & -0.00749 & $(0.443)$ \\
\hline number of hhd residents & 0.00267 & $(0.542)$ \\
\hline race: is hispanic & $-0.0353^{* *}$ & $(0.014)$ \\
\hline race: is black & 0.00658 & $(0.534)$ \\
\hline education: high-school graduate & 0.0115 & $(0.313)$ \\
\hline education: some college & $0.0351^{* * *}$ & $(0.006)$ \\
\hline education: college and above & 0.0155 & $(0.317)$ \\
\hline age in years & $-0.00298^{* * *}$ & $(0.000)$ \\
\hline not working for pay & 0.00437 & $(0.674)$ \\
\hline delayed word recall & 0.00226 & $(0.363)$ \\
\hline serial $7 \mathrm{~s}$ & -0.00408 & $(0.111)$ \\
\hline self-reported health & $-0.0128^{* * *}$ & $(0.001)$ \\
\hline Unconditional Probability & 0.085 & \\
\hline Observations & 3978 & \\
\hline 11 & -831.77 & \\
\hline $\begin{array}{l}\text { Note: We run Probit with robus } \\
\text { effects for the outcome of financi } \\
\text { associated with a increase of the } \\
\text { to pay bills. }\end{array}$ & $\begin{array}{l}\text { S.E. and rep } \\
\text { d distress. Sel } \\
\text { orobability of }\end{array}$ & $\begin{array}{l}\text { verage margina } \\
\text { failure is } \\
\text { t very difficult }\end{array}$ \\
\hline
\end{tabular}


Table 5: Net Wealth Variables and Self-Control Failure ingredients

\begin{tabular}{|c|c|c|c|c|c|c|}
\hline & \multicolumn{2}{|c|}{ net worth (IHS) } & \multicolumn{2}{|c|}{ net real wealth (IHS) } & \multicolumn{2}{|c|}{ net financial wealth (IHS) } \\
\hline Standards failure & $-0.510^{* *}$ & $(0.026)$ & $-0.350^{*}$ & $(0.071)$ & -0.192 & $(0.465)$ \\
\hline Monitoring failure & $-0.747^{*}$ & $(0.092)$ & 0.145 & $(0.660)$ & $-2.218^{* * *}$ & $(0.000)$ \\
\hline Commitment failure & $-1.179^{* * *}$ & $(0.004)$ & $-0.580^{*}$ & $(0.061)$ & $-0.747^{*}$ & $(0.092)$ \\
\hline total income (IHS) & $1.371^{* * *}$ & $(0.000)$ & $0.670^{* * *}$ & $(0.000)$ & $1.775^{* * *}$ & $(0.000)$ \\
\hline is a couple & $0.969 * * *$ & $(0.000)$ & $1.215^{* * *}$ & $(0.000)$ & 0.407 & $(0.172)$ \\
\hline number of hhd residents & $-0.220^{*}$ & $(0.088)$ & -0.00526 & $(0.960)$ & $-0.909 * * *$ & $(0.000)$ \\
\hline race: is hispanic & $-1.814^{* * *}$ & $(0.000)$ & $-1.042^{* * *}$ & $(0.009)$ & $-2.646^{* * *}$ & $(0.000)$ \\
\hline race: is black & $-1.630 * * *$ & $(0.000)$ & $-0.789 * * *$ & $(0.002)$ & $-2.576^{* * *}$ & $(0.000)$ \\
\hline education: high-school graduate & $0.812^{* * *}$ & $(0.007)$ & $0.741^{* * *}$ & $(0.003)$ & $0.868^{* *}$ & $(0.014)$ \\
\hline education: some college & $1.024^{* * *}$ & $(0.002)$ & $0.644^{* *}$ & $(0.021)$ & $1.485^{* * *}$ & $(0.000)$ \\
\hline education: college and above & $1.334^{* * *}$ & $(0.000)$ & $0.700^{* *}$ & $(0.014)$ & $2.631^{* * *}$ & $(0.000)$ \\
\hline age (years) & $0.138^{* * *}$ & $(0.000)$ & $0.0571^{* * *}$ & $(0.000)$ & $0.153^{* * *}$ & $(0.000)$ \\
\hline not working for pay & 0.240 & $(0.271)$ & -0.113 & $(0.527)$ & $1.262^{* * *}$ & $(0.000)$ \\
\hline delayed word recall & -0.00670 & $(0.888)$ & 0.0318 & $(0.476)$ & 0.0319 & $(0.600)$ \\
\hline serial $7 \mathrm{~s}$ & $0.196^{* * *}$ & $(0.004)$ & $0.123^{* *}$ & $(0.027)$ & $0.277^{* * *}$ & $(0.000)$ \\
\hline self-reported health & $0.547 * * *$ & $(0.000)$ & $0.304^{* * *}$ & $(0.000)$ & $0.657^{* * *}$ & $(0.000)$ \\
\hline net financial wealth (IHS) & & & $0.126^{* * *}$ & $(0.000)$ & & \\
\hline net real wealth (IHS) & & & & & $0.267^{* * *}$ & $(0.000)$ \\
\hline Observations & 4025 & & 4025 & & 4025 & \\
\hline Adj. $R^{2}$ & 0.203 & & 0.196 & & 0.291 & \\
\hline
\end{tabular}

Note: We run OLS with robust S.E. and report the average marginal effects of the self control ingredients.

For the real wealth regression we include financial wealth as an explanatory variable, and vice versa.

$p$-values in parentheses: ${ }^{*} p<0.1,{ }^{* *} p<0.05,{ }^{* * *} p<0.01$ 
Table 6: Financial Distress and Self-Control Failure ingredients

\begin{tabular}{lcc}
\hline \hline & \multicolumn{2}{c}{ Pr(Paying bills = very difficult) } \\
\hline Standards failure & 0.0139 & $(0.121)$ \\
Monitoring failure & $0.0437^{* * *}$ & $(0.002)$ \\
Commitment failure & $0.0506^{* * *}$ & $(0.000)$ \\
& & \\
net financial wealth (IHS) & $-0.00523^{* * *}$ & $(0.000)$ \\
net real wealth (IHS) & $-0.00287^{* * *}$ & $(0.000)$ \\
total income (IHS) & $-0.0241^{* * *}$ & $(0.000)$ \\
is a couple & -0.00809 & $(0.405)$ \\
number of hhd residents & 0.00320 & $(0.462)$ \\
race: is hispanic & $-0.0340^{* *}$ & $(0.017)$ \\
race: is black & 0.00659 & $(0.534)$ \\
education: high-school graduate & 0.0102 & $(0.369)$ \\
education: some college & $0.0314^{* *}$ & $(0.014)$ \\
education: college and above & 0.0108 & $(0.484)$ \\
age in years & $-0.00298^{* * *}$ & $(0.000)$ \\
not working for pay & 0.00456 & $(0.660)$ \\
delayed word recall & 0.00255 & $(0.305)$ \\
serial 7s & -0.00412 & $(0.107)$ \\
self-reported health & $-0.0111^{* * *}$ & $(0.005)$ \\
\hline Unconditional Probability & 0.085 & \\
Observations & 3978 & \\
ll & -823.81 & \\
\hline \hline Note: We run Probit with robust S.E. and report the average marginal
\end{tabular}

effects for the outcome of financial distress. Self-control failure is

associated with a increase of the probability of finding it very difficult

to pay bills.

$p$-values in parentheses: ${ }^{*} p<0.1,{ }^{* *} p<0.05,{ }^{* * *} p<0.01$ 
Table 7: Robustness Checks: Wealth Variables (Non-stockholders only)

\begin{tabular}{|c|c|c|c|c|c|c|}
\hline & \multicolumn{2}{|c|}{ "net worth (IHS) } & \multicolumn{2}{|c|}{ net real wealth (IHS) } & \multicolumn{2}{|c|}{ net financial wealth (IHS) } \\
\hline Self-control failure & $-0.844^{* * *}$ & $(0.001)$ & -0.219 & $(0.293)$ & $-0.788^{* * *}$ & $(0.009)$ \\
\hline total income (IHS) & $1.396^{* * *}$ & $(0.000)$ & $0.736^{* * *}$ & $(0.000)$ & $1.698^{* * *}$ & $(0.000)$ \\
\hline is a couple & $1.214^{* * *}$ & $(0.000)$ & $1.446^{* * *}$ & $(0.000)$ & 0.255 & $(0.494)$ \\
\hline number of hhd residents & -0.206 & $(0.159)$ & -0.0176 & $(0.882)$ & $-0.860 * * *$ & $(0.000)$ \\
\hline race: is hispanic & $-1.553^{* * *}$ & $(0.002)$ & $-0.886^{* *}$ & $(0.033)$ & $-2.097 * * *$ & $(0.000)$ \\
\hline race: is black & $-1.386^{* * *}$ & $(0.000)$ & $-0.706^{* *}$ & $(0.014)$ & $-2.133^{* * *}$ & $(0.000)$ \\
\hline education: high-school graduate & $0.587^{*}$ & $(0.083)$ & $0.627^{* *}$ & $(0.024)$ & $0.648^{*}$ & $(0.097)$ \\
\hline education: some college & $0.679^{*}$ & $(0.080)$ & 0.439 & $(0.179)$ & $0.929 * *$ & $(0.044)$ \\
\hline education: college and above & $0.899 * *$ & $(0.034)$ & $0.621^{*}$ & $(0.074)$ & $1.952^{* * *}$ & $(0.000)$ \\
\hline age in years & $0.159^{* * *}$ & $(0.000)$ & $0.0658^{* * *}$ & $(0.000)$ & $0.166^{* * *}$ & $(0.000)$ \\
\hline not working for pay & 0.188 & $(0.523)$ & -0.177 & $(0.454)$ & $1.144^{* * *}$ & $(0.002)$ \\
\hline delayed word recall & -0.0161 & $(0.799)$ & 0.0295 & $(0.601)$ & 0.0115 & $(0.881)$ \\
\hline serial $7 \mathrm{~s}$ & $0.242^{* * *}$ & $(0.004)$ & $0.163^{* *}$ & $(0.016)$ & $0.313^{* * *}$ & $(0.001)$ \\
\hline self-reported health & $0.635^{* * *}$ & $(0.000)$ & $0.399 * * *$ & $(0.000)$ & $0.647^{* * *}$ & $(0.000)$ \\
\hline net financial wealth (IHS) & & & $0.118^{* * *}$ & $(0.000)$ & & \\
\hline net real wealth (IHS) & & & & & $0.250^{* * *}$ & $(0.000)$ \\
\hline Observations & 2880 & & 2880 & & 2880 & \\
\hline Adj. $R^{2}$ & 0.167 & & 0.177 & & 0.223 & \\
\hline
\end{tabular}

Note: We run OLS with robust S.E. and the coefficients can be interpreted as the average marginal effects of self control failure. For the real wealth regression we include financial wealth as an explanatory variable, and vice versa.

$p$-values in parentheses: ${ }^{*} p<0.1,{ }^{* *} p<0.05,{ }^{* * *} p<0.01$ 
Table 8: Robustness Checks: Probability of Financial Distress (Non-stockholders only)

\begin{tabular}{lcc}
\hline \hline & Pr(Paying bills $=$ & very difficult) \\
\hline Self-control failure & $0.0464^{* * *}$ & $(0.000)$ \\
net real wealth (IHS) & $-0.00541^{* * *}$ & $(0.000)$ \\
total income (IHS) & $-0.0388^{* * *}$ & $(0.000)$ \\
is a couple & 0.00743 & $(0.596)$ \\
number of hhd residents & 0.000829 & $(0.885)$ \\
race: is hispanic & $-0.0387^{* *}$ & $(0.045)$ \\
race: is black & 0.0233 & $(0.109)$ \\
education: high-school graduate & 0.0149 & $(0.347)$ \\
education: some college & $0.0431^{* *}$ & $(0.017)$ \\
education: college and above & 0.0165 & $(0.456)$ \\
age (years) & $-0.00506^{* * *}$ & $(0.000)$ \\
not working for pay & -0.00584 & $(0.694)$ \\
delayed word recall & 0.00284 & $(0.410)$ \\
serial 7s & $-0.00605^{*}$ & $(0.096)$ \\
self-reported health & $-0.0238^{* * *}$ & $(0.000)$ \\
\hline Unconditional Probability & 0.111 & \\
Observations & 3978 & \\
$l l$ & -804.38 & \\
\hline \hline$p$-values in parentheses & &
\end{tabular}

${ }^{*} \mathrm{p}_{\mathrm{i}} 0.1,{ }^{* *} \mathrm{p} \mathrm{i} 0.05, * * * \mathrm{p} \mathrm{i} 0.01$ 
Table 9: Net Wealth and Self-control Failure (alternative measure)

\begin{tabular}{|c|c|c|c|c|c|c|}
\hline & \multicolumn{2}{|c|}{ net worth (IHS) } & \multicolumn{2}{|c|}{ net real wealth (IHS) } & \multicolumn{2}{|c|}{ net financial wealth (IHS) } \\
\hline Self-control failure & $-0.689^{* * *}$ & $(0.000)$ & $-0.314^{* *}$ & $(0.037)$ & $-0.621^{* * *}$ & $(0.005)$ \\
\hline total income (IHS) & $1.363^{* * *}$ & $(0.000)$ & $0.673^{* * *}$ & $(0.000)$ & $1.748^{* * *}$ & $(0.000)$ \\
\hline is a couple & $0.980^{* * *}$ & $(0.000)$ & $1.231^{* * *}$ & $(0.000)$ & 0.383 & $(0.199)$ \\
\hline number of hhd residents & $-0.217^{*}$ & $(0.092)$ & -0.00611 & $(0.953)$ & $-0.900 * * *$ & $(0.000)$ \\
\hline race: is hispanic & $-1.837^{* * *}$ & $(0.000)$ & $-1.057 * * *$ & $(0.008)$ & $-2.665^{* * *}$ & $(0.000)$ \\
\hline race: is black & $-1.651^{* * *}$ & $(0.000)$ & $-0.786^{* * *}$ & $(0.002)$ & $-2.634^{* * *}$ & $(0.000)$ \\
\hline education: high-school graduate & $0.826^{* * *}$ & $(0.006)$ & $0.755^{* * *}$ & $(0.003)$ & $0.867^{* *}$ & $(0.015)$ \\
\hline education: some college & $1.048^{* * *}$ & $(0.001)$ & $0.672^{* *}$ & $(0.016)$ & $1.466^{* * *}$ & $(0.000)$ \\
\hline education: college and above & $1.326^{* * *}$ & $(0.000)$ & $0.723^{* *}$ & $(0.011)$ & $2.561^{* * *}$ & $(0.000)$ \\
\hline age in years & $0.139^{* * *}$ & $(0.000)$ & $0.0570^{* * *}$ & $(0.000)$ & $0.154^{* * *}$ & $(0.000)$ \\
\hline not working for pay & 0.242 & $(0.268)$ & -0.122 & $(0.496)$ & $1.293^{* * *}$ & $(0.000)$ \\
\hline delayed word recall & -0.00570 & $(0.905)$ & 0.0326 & $(0.467)$ & 0.0319 & $(0.601)$ \\
\hline serial $7 \mathrm{~s}$ & $0.198^{* * *}$ & $(0.004)$ & $0.124^{* *}$ & $(0.025)$ & $0.279^{* * *}$ & $(0.000)$ \\
\hline self-reported health & $0.557^{* * *}$ & $(0.000)$ & $0.306^{* * *}$ & $(0.000)$ & $0.670^{* * *}$ & $(0.000)$ \\
\hline net financial wealth (IHS) & & & $0.126^{* * *}$ & $(0.000)$ & & \\
\hline net real wealth (IHS) & & & & & $0.268^{* * *}$ & $(0.000)$ \\
\hline Observations & 4025 & & 4025 & & 4025 & \\
\hline Log-likelihood & -12354.19 & & -11730.07 & & -13250.88 & \\
\hline
\end{tabular}

Note: We run OLS with robust S.E. and the coefficients can be interpreted as the average marginal effects of self control failure. For the real wealth regression we include financial wealth as an explanatory variable, and vice versa.

$p$-values in parentheses: ${ }^{*} p<0.1,{ }^{* *} p<0.05,{ }^{* * *} p<0.01$ 
Table 10: Robustness Checks: Financial Distress (alternative measure)

\begin{tabular}{lcc}
\hline \hline & \multicolumn{2}{c}{ Pr(Paying bills = very difficult) } \\
\hline Self-control failure & $0.0558^{* * *}$ & $(0.000)$ \\
& & $(0.000)$ \\
net real wealth (IHS) & $-0.00454^{* * *}$ & $(0.000)$ \\
total income (IHS) & $-0.0374^{* * *}$ & $(0.761)$ \\
is a couple & -0.00309 & $(0.156)$ \\
number of hhd residents & 0.00615 & $(0.035)$ \\
race: is hispanic & $-0.0323^{* *}$ & $(0.142)$ \\
race: is black & 0.0164 & $(0.467)$ \\
education: high-school graduate & 0.00897 & $(0.047)$ \\
education: some college & $0.0274^{* *}$ & $(0.903)$ \\
education: college and above & 0.00199 & $(0.450)$ \\
age (years) & $-0.00429^{* * *}$ & $(0.334)$ \\
not working for pay & -0.00826 & $(0.000)$ \\
delayed word recall & 0.00249 & \\
serial 7s & $-0.00460^{*}$ & \\
self-reported health & $-0.0196^{* * *}$ & \\
\hline Unconditional Probability & 0.085 & \\
Observations & 3978 & \\
ll & -893.87 & \\
\hline \hline Note: We run Probit with robust S.E. and report the average marginal \\
effects for the outcome of financial distress. Self-control failure is \\
associated with a increase of the probability of finding it very difficult \\
to pay bills. \\
$p$-values in parentheses: $* p<0.1, * * p<0.05, * * * * 01$ \\
\hline
\end{tabular}


Table 11: Robustness Checks: Net Wealth and Self-control Failure (using data aggregated to the household level)

\begin{tabular}{|c|c|c|c|c|c|c|}
\hline \multirow[b]{2}{*}{ Self-control failure } & \multicolumn{2}{|c|}{ net worth (IHS) } & \multicolumn{2}{|c|}{ " net real wealth (IHS) } & \multicolumn{2}{|c|}{ " net financial wealth (IHS) } \\
\hline & $-0.657^{* * *}$ & $(0.000)$ & -0.237 & $(0.111)$ & $-0.784^{* * *}$ & $(0.000)$ \\
\hline total income (IHS) & $1.423^{* * *}$ & $(0.000)$ & $0.691^{* * *}$ & $(0.000)$ & $1.774^{* * *}$ & $(0.000)$ \\
\hline is a couple & $1.173^{* * *}$ & $(0.000)$ & $1.341^{* * *}$ & $(0.000)$ & 0.391 & $(0.198)$ \\
\hline number of hhd residents & $-0.229^{*}$ & $(0.074)$ & 0.00667 & $(0.946)$ & $-0.880 * * *$ & $(0.000)$ \\
\hline race: is hispanic & $-1.300^{* * *}$ & $(0.001)$ & $-0.708^{* *}$ & $(0.040)$ & $-2.338 * * *$ & $(0.000)$ \\
\hline race: is black & $-1.517^{* * *}$ & $(0.000)$ & $-0.666^{* * *}$ & $(0.008)$ & $-2.714^{* * *}$ & $(0.000)$ \\
\hline education: high-school graduate & $0.931^{* * *}$ & $(0.004)$ & $0.884^{* * *}$ & $(0.001)$ & $0.961^{* * *}$ & $(0.010)$ \\
\hline education: some college & $1.279^{* * *}$ & $(0.000)$ & $0.843^{* * *}$ & $(0.004)$ & $1.701^{* * *}$ & $(0.000)$ \\
\hline education: college and above & $1.553^{* * *}$ & $(0.000)$ & $0.878^{* * *}$ & $(0.003)$ & $2.627^{* * *}$ & $(0.000)$ \\
\hline age in years & $0.160 * * *$ & $(0.000)$ & $0.0744^{* * *}$ & $(0.000)$ & $0.164^{* * *}$ & $(0.000)$ \\
\hline not working for pay & 0.206 & $(0.408)$ & -0.125 & $(0.550)$ & $1.054^{* * *}$ & $(0.001)$ \\
\hline delayed word recall & 0.0774 & $(0.118)$ & 0.0689 & $(0.144)$ & $0.112^{*}$ & $(0.077)$ \\
\hline serial $7 \mathrm{~s}$ & $0.159^{* *}$ & $(0.025)$ & $0.101^{*}$ & $(0.082)$ & $0.268^{* * *}$ & $(0.001)$ \\
\hline self-reported health & $0.571^{* * *}$ & $(0.000)$ & $0.333^{* * *}$ & $(0.000)$ & $0.682^{* * *}$ & $(0.000)$ \\
\hline net financial wealth (IHS) & & & $0.126^{* * *}$ & $(0.000)$ & & \\
\hline net real wealth (IHS) & & & & & $0.266^{* * *}$ & $(0.000)$ \\
\hline Observations & 4231 & & 4231 & & 4231 & \\
\hline Adj. $R^{2}$ & 0.200 & & 0.192 & & 0.289 & \\
\hline
\end{tabular}

self control failure. Compared to the baseline specification, we aggregate the self-control failure measure and the demographic data of the household, instead of using the financial respondent's only. The variables include race, education, age, working status, cognitive abilities and health. For the real wealth regression we include financial wealth as an explanatory variable, and vice versa.

$p$-values in parentheses: ${ }^{*} p<0.1,{ }^{* *} p<0.05,{ }^{* * *} p<0.01$ 


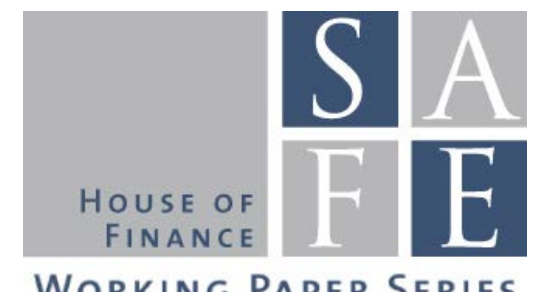

WORKING PAPER SERIES

\section{Recent Issues}

No. 68 Tobias Tröger

No. 67 Sascha Baghestanian, Paul J. Gortner, Joel van der Weele

No. 66 Tobias Tröger

No. 65 Elia Berdin, Helmut Gründl

No.64 Daniel Herbold

No.63 Nicola Fuchs-Schündeln, Michael Haliassos

No.62 Patrick Behr, Alejandro H. Drexler, Reint Gropp, Andre Guettler

No. 61 Iñaki Aldasoro, Mike Seiferling

No. 60 Stefano Colonnello, Giuliano Curatola, Ngoc Giang Hoang

No. 59 Daniel Harenberg, Alexander Ludwig

No. 58 Michael Haliassos, Thomas Jansson, Yigitcan Karabulut

No. 57 Brigitte Haar

No. 56 Giuliano Curatola, Michael Donadelli, Alessandro Gioffré, Patrick Grüning

No. 55 Jan Pieter Krahnen, Peter Ockenfels, Christian Wilde
How Special Are They? - Targeting Systemic Risk by Regulating Shadow Banking

Peer Effects and Risk Sharing in Experimental Asset Markets

\section{Corporate Groups}

The Effects of a Low Interest Rate Environment on Life Insurers

A Repeated Principal-Agent Model with Onthe-Job Search

Does Product Familiarity Matter for Participation?

Financial Incentives and Loan Officers Behavior: Multitasking and Allocation of Effort Under an Incomplete Contract

Vertical Fiscal Imbalances and the Accumulation of Government Debt

Executive Compensation Structure and Credit Spreads

Social Security and the Interactions Between Aggregate and Idiosyncratic Risk

Incompatible European Partners? Cultural Predispositions and Household Financial Behavior

Financial Regulation in the EU - Cross-Border Capital Flows, Systemic Risk and the European Banking Union as Reference Points for EU Financial Market Integration

Austerity, Fiscal Uncertainty, and Economic Growth

Measuring Ambiguity Aversion: A Systematic Experimental Approach 